\title{
INDISCIPLINA NA ESCOLA: UMA APROXIMAÇÃO À LUZ DE WILFRED BION
}

\author{
Ana Archangelo ${ }^{1}$
}

RESUMO: O termo indisciplina cobre fenômenos bastante diversos nas escolas. Baseado nas ideias de Bion, este artigo discutirá que a indisciplina se define como experiências emocionais não toleradas nem processadas, tanto individual como institucionalmente, as quais estão em busca de processamento mental. Este trabalho concluirá que cabe ao adulto responsável pelo encaminhamento das medidas disciplinadoras não a função de correção, mas a de continência das ansiedades presentes nos episódios relacionados à indisciplina.

Palavras-chave: Indisciplina. Elementos-beta. Função-alfa. Identificação projetiva. Psicanálise e educação.

\section{INDISCIPLINE AT SCHOOL: AN APPROACH IN THE LIGHT OF WILFRED BION}

\begin{abstract}
The term indiscipline covers a variety of quite distinct phenomena in schools. Based on Bion's ideas, this article will argue that indiscipline defines itself as individual and institutional non-tolerated and non-processed emotional experiences, which are in search of mental processing. This work will conclude that the role of the adult responsible for taking the disciplinary measures should not be a corrective function, but, instead, to provide containment for the anxieties that permeate the episodes associated to the indiscipline in question.
\end{abstract}

Keywords: Indiscipline. Beta-elements. Alpha-function. Projective identification. Psychoanalysis and education.

\section{INDISCIPLINA EN LA ESCUELA: UNA APROXIMACIÓN A LA LUZ DE WILFRED BION}

RESUMEN: El término indisciplina barca fenómenos muy diversos en el ámbito escolar. Basado en las ideas de Bion, este artículo se propone a discutir la definición de indisciplina como experiencias emocionales que no son toleradas tampoco procesadas, tanto en el aspecto individual como institucional, y que están en búsqueda de procesamiento mental. Se concluye que no le cabe al

*O texto é resultado de projeto de pesquisa fomentado pela Fapesp, linha "Melhoria do Ensino" (processo n. 2010/08739-7).

1.Universidade Estadual de Campinas - Faculdade de Educação - Departamento de Psicologia Educacional - Campinas (SP), Brasil. E-mail: ana.archangelo@gmail.com 
adulto responsable por el reenvío de las medidas de disciplina la función de corrección, sino la de contener las ansiedades presentes en los episodios relacionados con la indisciplina.

Palabras-clave: Indisciplina. Elementos-beta. Función-alfa. Identificación proyectiva. Psicoanálisis y educación.

\section{Introdução}

A

reflexão aqui apresentada é síntese de um processo de estudo e análise de uma experiência vivida em uma escola pública brasileira, de Ensino Fundamental, na qual as ocorrências de indisciplina

passaram a ser pensadas à luz dos conceitos de elementos-beta, função-alfa e elementos-alfa, bem como dos conceitos de relação continente-contido, de Bion (2004a). Inicialmente pautada pela correção, a escola tinha alguns padrões de resposta para as ocorrências de indisciplina. Esses consistiam, basicamente, em: 1) orientação para que o aluno aceitasse as exigências dos professores; 2) convocação dos pais e exigência do compromisso, da parte deles, para com o bom comportamento de seus filhos na escola; e 3) suspensão. Essa última, diferentemente do que se possa imaginar, era medida utilizada com frequência, não como recurso extremo ou exceção. Por essa razão, vários alunos eram sistematicamente obrigados a se ausentar da escola durante vários dias. Ao contrário do que se esperava, porém, tal punição não coibia novos "atos indisciplinados" e parecia fazer com que os mesmos alunos voltassem cada vez mais frequentemente à sala do diretor, tendo cometido novas "infrações", o que exigia que a direção lançasse mão de suspensões por períodos cada vez mais longos.

Durante dois anos, alguns professores e um vice-diretor da escola estiveram envolvidos em um projeto que previa encontros semanais, nos quais eram abordados, entre outros assuntos, episódios escolares rotineiros, além de serem estudados alguns textos de autores da psicanálise ou de inspiração psicanalítica. Em virtude das inúmeras queixas de indisciplina na escola, esse passou a ser um tema de preocupação do grupo e o vice-diretor, mais diretamente implicado com a intervenção sobre as ocorrências de indisciplina, foi convidado a organizar o registro sistemático de tais ocorrências, para análise longitudinal.

A partir das alarmantes constatações iniciais e do estudo empreendido pelo grupo, a intervenção da direção da escola nos episódios de indisciplina, gradualmente, deixou de ser balizada apenas pela ideia de controle e correção do aluno e passou a ser pautada pela escuta e pelo acolhimento do sofrimento presente nessas situações. A análise de alguns casos exemplares, a diminuição progressiva e sensível das "ocorrências" de indisciplina e o movimento interno à instituição na busca por meios para atender a algumas das necessidades de alunos e professores foram apresentados em Archangelo (2014). O presente texto tem o desafio de formular alguns pressupostos acerca da produção, da circulação e do manejo do fenômeno chamado indisciplina, à luz das ideias de um autor alheio ao discurso educacional, mas que contribuiu com uma intervenção propriamente pedagógica na escola aqui citada.

\section{Para Entender por que Bion Pode Ser Útil ao Tema da Indisciplina Escolar}

Bion jamais tratou da indisciplina escolar. No entanto, suas ideias sobre a constituição e o desenvolvimento do psiquismo humano ecoam sobre todas as situações em que pessoas experimentam o viver com o outro. Para Bion (2004a), qualquer experiência entre o sujeito e o mundo (outro objeto, outra 
pessoa ou situação) evoca impressões sensoriais que vêm sempre acompanhadas de uma qualidade emocional. Portanto, todas as nossas experiências carregam um vetor afetivo a ser processado, elaborado ou "digerido". Toda experiência que temos com um objeto ou uma pessoa implica impressões sensoriais (p. ex., frio e quente), que são carregadas de uma resposta emocional, não sensorial (agradável, violenta etc.).

Ao tocar uma xícara de chá quente, percebo não apenas a temperatura, mas registro a agradável experiência de aquecer a mão fria em um dia de inverno. A mesma xícara de chá quente, porém, pode, pelo contrário, constituir experiência de violência, caso a alta temperatura chegue a queimar minha mão. Posso, ainda, ansiar pela experiência agradável que um chocolate quente me traria, sem que ele esteja disponível. Algo em meu corpo dará sinais de minha capacidade ou incapacidade momentânea de imaginar e verbalizar meu desejo e/ou minha frustração.

A esse conjunto indissociável entre a impressão sensorial e o vetor emocional da experiência, Bion (2004a) dá o nome experiência emocional - ou seja, a experiência emocional não é apenas relacionada aos órgãos sensoriais, mas também à qualidade afetiva que o psiquismo confere a esse contato eu-mundo e ao que se pode imaginar e criar a partir dele. Em igual medida, podemos dizer que aspectos afetivos de nosso psiquismo são indissociáveis dessa experiência no nível de nosso corpo.

Ainda segundo o autor, os elementos resultantes da experiência emocional não podem ser armazenados como memória tampouco se prestam ao pensamento onírico, a menos que sejam processados mentalmente. Para fazer-se entender, o autor explora a metáfora da digestão, afirmando que nossas experiências, para serem convertidas em memória ou em algo pensável, antes precisariam de uma "digestão mental"; ou seja, do processamento ou da "digestão" desses elementos aos quais Bion chamou elementos-beta.

Bion (2004a) afirma que o elemento-beta, tal e qual é produzido na experiência, seria uma "coisa em si”, que necessita de uma função mental capaz de processá-la. Apenas após esse processamento o elementobeta ficaria à disposição do pensamento e do armazenamento. A metáfora da digestão coloca em relevo justamente esta qualidade: o alimento só serve à nutrição depois que sofre a ação de uma função que o transforma em algo absorvível pelo organismo. Antes disso, serve somente para ocupar espaço no estômago ou ser expelido. O mesmo ocorreria com os produtos de nossas experiências: ou são processados por uma função mental, ou apenas servem à evacuação ou à fragmentação.

Também como no fenômeno da digestão, enquanto houver uma "coisa" indigesta ou indigerível no estômago, o sujeito é incapaz de usufruir de outro alimento. Todos sabemos que, se algo não nos cai bem, só conseguimos comer novamente depois de normalizada a digestão, seja mediante reações que permitam que seja expelida a coisa indigerível, seja mediante medidas externas (p. ex., medicação) que recomponham a dinâmica digestória. Às vezes, passamos dias ingerindo apenas o mínimo necessário à manutenção de outras funções corporais, até que a função digestória se estabilize. Enquanto isso, não apenas recusamos grande parte do alimento que nos é oferecido, como também perdemos parcela do entusiasmo e da vitalidade que nos caracteriza.

Bion (2004a) diz que, no plano mental, o mesmo ocorre com as impressões sensoriais e as emoções. A essa função mental que processa/digere os elementos-beta, o autor dá o nome função-alfa, a qual seria, portanto, responsável por tornar alimento "a coisa" não digerida da experiência, transformando-a em algo pronto a ser utilizado pela mente, seja em forma de pensamento, seja em forma de memória, sonho etc. Aos produtos desse processamento, o autor dá o nome elementos-alfa: aqueles que podem vir a ser armazenados como memória e utilizados nas atividades de pensar e sonhar.

Quando não há função-alfa disponível, os elementos-beta são como o alimento/coisa que intoxica: são transformados em fragmentos e expulsos, tal como no vômito. Exigem que o corpo não apenas se livre deles, mas recuse outros alimentos, provocando certa impressão de desinteresse pelo que se passa ao redor. 
Nessa situação, a expulsão da "coisa" indigesta e fragmentada agride o aparelho digestório tanto quanto a experiência emocional não processada agride o psiquismo do sujeito ou, em outras palavras, provoca sofrimento psíquico. Ao mesmo tempo, o vômito faz da "coisa" indigesta algo que se espalha sem controle nem finalidade pelo entorno. Os elementos-beta não processados pela função-alfa fazem o mesmo, ao que Bion (2004a) chamou identificação projetiva: a expulsão desordenada dos fragmentos não processados ou não digeridos da experiência emocional do sujeito, os quais se espalham pelo ambiente e atingem a todos, provocando neles algum impacto.

Segundo Bion (2004a), ao nascer, não temos ainda a função-alfa desenvolvida. Vivemos nossos estados emocionais na sua forma bruta, o que produz muita ansiedade - em especial ansiedade persecutória (KLEIN, 1991), cuja característica fundamental é o temor pelo aniquilamento do ego. No entanto, não estamos sozinhos nessa experiência, mas sim acompanhados sempre de um outro - usualmente, mas não apenas, a mãe, nos estágios iniciais da vida. Esse outro, em tese, disporia da função-alfa e seria capaz de ajudar no processamento dos estados emocionais do bebê. Portanto, ao chorar desesperadamente de fome ou dor, o bebê estaria expulsando de si sua ansiedade (elemento-beta). Ao fazer isso, evocaria no outro que lhe dá suporte uma resposta. Tendo sorte, a resposta seria justamente o oferecimento daquilo que ao sujeito é necessário naquele momento: o alimento, um banho morno, o colo, um remédio ou outra providência e, somado a isso, o conforto de ter sido compreendido em sua necessidade.

Em outras palavras, aquilo que o bebê não sabe o que é, mas que nele provoca sofrimento e ansiedade, vai sendo expulso pelo choro, pelo movimento de contorcer-se etc., até o ponto de comunicar ao outro a necessidade que o bebê apresenta naquele momento. Ao mecanismo envolvido nessa ação do bebê, Bion (2004a) dá o nome identificação projetiva realista. O termo realista significa que essa é uma atividade necessária à sobrevivência do bebê, uma vez que seria, nessa etapa da vida, um dos únicos recursos psíquicos disponíveis para ele estabelecer alguma comunicação com o outro, com o mundo. Portanto, essa identificação projetiva teria um caráter comunicativo, cabendo à mãe estar sensível àquilo que lhe é comunicado, embora nem sempre isso ocorra.

O que o autor quer dizer é que, ao nascer, o bebê não tem recurso interno suficiente para processar por conta própria sua ansiedade e seu medo de morrer; para entender de onde eles vêm e a que se referem; e para compreender como podem ser atenuados. Em outras palavras, quando nascemos, não temos função-alfa disponível para o processamento de nossas experiências. Voltando à metáfora digestória, podemos dizer que não dispomos inicialmente de aparelho mental de digestão ou processamento das ansiedades que sentimos desde o nascimento. Essa função deverá ser desempenhada pelo adulto.

É a mãe (ou outro cuidador) que traduz e discrimina o choro de sono, de fome ou de dor e oferece a resposta adequada; que faz com que o choro cesse e a ansiedade seja atenuada. Quando isso ocorre, o bebê pode retomar o contato consigo mesmo e com as experiências que teve, bem como entrar em contato com a capacidade de compreensão ofertada pela mãe. Ao intuir e identificar a razão do choro, a mãe está processando os elementos da experiência do bebê até esses se tornarem a informação necessária para que ela saiba o que fazer para ajudá-lo. Repetidas experiências como essas fazem com que, progressivamente, o bebê passe a aceitar a fome e a dor como algo que se pode tolerar e, ainda, sobre o que se pode pensar.

O que Bion (1994) está dizendo é que, inicialmente, a digestão da experiência emocional é feita pela mãe (ou quem a substitua), no lugar do bebê, tornando a ansiedade tolerável para ele. Ao viver essa mudança, o bebê não apenas tomaria para si sua própria experiência, agora tolerável, mas também a capacidade desse outro de processar o sofrimento. Em suma, a função-alfa, que permite ao sujeito processar suas experiências emocionais tornando-as toleráveis e "pensáveis", nasceria do contato do bebê com o outro, com a capacidade da qual o outro fez uso no processamento da ansiedade do bebê. 
Segundo Bion (1994), tornamo-nos tanto mais capazes de processar e digerir nossas experiências quanto mais oportunidade tenhamos tido de estar em companhia de pessoas que nos tenham ofertado a sua própria capacidade no momento em que precisávamos. Se tudo correr bem, aos poucos abriremos mão da identificação projetiva, já que nos tornaremos capazes de tolerar nossas experiências e as frustrações decorrentes delas. Sendo capazes de tolerar a frustração que advém da experiência, suportamos ser atravessados pela ansiedade e acolhemos mentalmente os elementos que precisam ser processados, digeridos e pensados. É dessa capacidade de processar que nasce a capacidade de pensar. Os pensamentos sobre nossas experiências são, na origem, esses elementos-beta acolhidos pela função-alfa; tornam-se pensamentos quando já processados. Como afirma Bion (1994), somente os elementos-alfa (elementos da experiência que foram tolerados pela mente e processados pela função-alfa) são passíveis de serem pensados. Portanto, ao longo do desenvolvimento, substituímos, progressivamente, a identificação projetiva realista pela função-alfa. Em vez de expulsarmos os elementos frustrantes da experiência, acolhemos a necessidade de pensá-los. ${ }^{1}$ Contudo, todos sabemos que isso não ocorre sempre: nem no mesmo nível nas diferentes esferas de nossa existência, nem igualmente com todos os sujeitos. Alguns são privados do suporte que o adulto deve dar nesse processo inicial da vida; outros vivem repetidas experiências de profundo sofrimento (p. ex., em situações de desamparo, injustiça, discriminação e preconceito, exclusão social etc.), sem tempo nem suporte ambiental suficientes para o processamento delas; outros ainda vivem experiências traumáticas, que tornam tanto o montante de sofrimento por demais intenso quanto a área da mente tomada pela ansiedade por demais extensa - contaminando e danificando os recursos mentais que até então estavam disponíveis para o acolhimento e o processamento dessas experiências. Nessas circunstâncias, o que fazer com esses estados emocionais, quando a função-alfa não se desenvolveu suficientemente ou foi prejudicada por algum acontecimento da vida?

Segundo Bion (2004a), permaneceríamos fazendo uso da identificação projetiva. Nesse caso, ela já não seria predominantemente realista ou uma forma de comunicar o estado de sofrimento ao outro, mas sim de fugir "da verdade da experiência"; ou seja, um modo de o sujeito evadir-se do sofrimento, na esperança de controlá-lo. A expulsão dos estados emocionais brutos teria o caráter preponderante de fuga da frustração e da ansiedade decorrentes da experiência, pelo que tenderia a ser uma expulsão violenta e desordenada dos elementos-beta. Esses seriam, mediante um pensamento onipotente (BION, 1994), depositados no interior do psiquismo do outro, de modo que não fossem reconhecidos como sofrimento próprio. Ou seja, se a funçãoalfa é aquela que nos permite digerir o próprio sofrimento e torná-lo algo tolerável e "pensável" como parte de nós mesmos, a ausência ou a insuficiência momentânea dessa função nos obrigaria à atitude de "fazer picadinho" dessa experiência e "evacuá-la", até o ponto de torná-la irreconhecível, como se não fosse nossa.

Os efeitos da ausência de função-alfa são vários, sendo talvez o mais evidente a violência com que o sujeito expele partes de suas experiências e repele aquilo que lhe é oferecido, assim como o estômago tomado pela comida estragada expele-a e repele outras tentativas de alimentação. Outro efeito seria certa perda de interesse por algumas novas experiências - ou um interesse inicial que se mostra repulsivo logo adiante. Por fim, o efeito de longo prazo, caso perdure a ausência de função-alfa, é o distanciamento do sujeito em relação à sua própria experiência de ser, já que, em vez de se permitir ser atravessado por ela e de se constituir a partir dela, o sujeito se empenharia em livrar-se dela, contaminando todo o ambiente com esse sofrimento, cuja origem o sujeito não reconhece. Todos são acometidos pelo que é expulso, mas ninguém sabe de onde aquilo vem, pois, como a experiência foi fragmentada, ficaria "irreconhecível".

Quando, numa organização, o espaço para o pensamento sobre sentimentos dolorosos e ansiedades não existe ou é recusado, esses se tornam provavelmente tóxicos e disruptivos em seus efeitos, materializados em doença e conflito entre as pessoas. Portanto, para pensarmos a indisciplina à luz dos conceitos de Bion, 
é necessário problematizarmos a natureza dos chamados atos indisciplinados, sua origem e seu sentido, em termos institucionais, para, somente então, pensarmos nas possibilidades de manejo desse problema.

\section{A Indisciplina da Escola Pensada à Luz dos Pressupostos Bionianos}

Considerando-se o anteriormente exposto, podemos refletir sobre a indisciplina a partir dos seguintes pressupostos.

\section{Primeiro pressuposto}

A indisciplina se refere à manifestação, em atos, palavras ou recusas, de elementos-beta produzidos na experiência, sem uma função-alfa correspondente capaz de processá-los.

A situação mais comumente lembrada para ilustrar esse pressuposto é a de alunos cuja experiência doméstica ou social seja de negligência ou violência. Tais alunos tendem a chegar à escola tomados por uma ansiedade intolerável (elementos-beta) e momentaneamente sem condições (função-alfa) de processar tal sofrimento. Nesse cenário, podem não apenas se recusar a realizar as atividades escolares, como também reagir desproporcionalmente aos apelos do professor para que as realizem.

Todavia, frustrações e ausência de suporte para processá-las não são exclusividade dos ambientes extraescolares. Muito pelo contrário: originam-se e se perpetuam, em muitos casos, no interior da própria escola. São muitos os alunos, por exemplo, que, diante de alguma dificuldade de aprendizagem, encontram, por parte da instituição e de seus membros, apenas indiferença ou críticas ao seu baixo rendimento.

Não são poucas as escolas que imaginam a relação de ensino-aprendizagem como unilateral: se a escola ensina, então, consequentemente, o aluno deve aprender. Não há espaço para autocrítica, revisão de rumos e compartilhamento de dúvidas e dificuldades, o que significa, aos olhos do aluno, indiferença. Em alguns casos, essa falta de espaço constitui uma violência, já que a responsabilidade sobre as experiências de frustração decorrentes de uma relação entre professor, conhecimento e aluno é toda depositada sobre um dos polos da relação - o aprendiz.

De qualquer modo, tanto em cenários que envolvam o ambiente externo à escola quanto naqueles em que os elementos-beta sejam produzidos no interior da instituição, podemos dizer que o aluno não tem, ao menos momentaneamente, a função-alfa necessária para transformar seu sofrimento em algo capturável por sua mente, seja sob a forma de pensamento, seja como palavra.

Como a função-alfa capaz de processar os elementos-beta provenientes de uma experiência não necessariamente precisa estar disponível na mente do sujeito da experiência, mas deve estar também na mente de outros que se relacionem com ele, chegamos ao pressuposto seguinte.

\section{Segundo pressuposto}

A indisciplina, antes de ser considerada como tal, é um conjunto de elementos-beta em busca de uma função-alfa.

Voltando às situações mencionadas no primeiro pressuposto, o professor pode ser aquele que acolhe os elementos-beta do aluno. Se tiver à disposição sua função-alfa, naquele momento, ela poderá ajudá-lo a processá-los. Tal processamento pode ser de diferentes níveis, mas sempre tendo como base a natureza de sua atividade profissional. No caso de elementos-beta exclusivamente resultantes da experiência frustrante de aprendizagem "malsucedida”, caberá à função-alfa do professor não apenas proporcionar 
diferentes meios e estratégias para que o aluno aprenda, mas acolher o ódio, o ressentimento e o sentimento de impotência ou inadequação que perpassam a relação desse aluno com o professor, com a disciplina e com o conteúdo específico. Acolher tais sentimentos significa legitimá-los como elementos intrínsecos à aventura de aprendizagem. Nada mais reconfortante do que perceber que fazemos tão mais parte da comunidade humana quanto mais somos capazes de experimentar sentimentos intensos, e nem sempre prazerosos.

Também a capacidade de rever-se em sua atividade pedagógica - seja didática, seja metodológica, seja de escolha de conteúdo ou de instrumentos de avaliação - compõe essa capacidade de processamento do professor. Tomar a dificuldade do aluno como algo pensável em vários níveis e direções divide a responsabilidade pela frustração e, sobretudo, dá mostras de como fazer uso da função-alfa - investigando, levantando as mais diversas hipóteses e colocando-se aberto ao que o aproxima da verdade da experiência (BION, 2004b).

Quando os elementos-beta são resquícios de experiências externas à escola, a situação torna-se um tanto mais complexa, pois ao professor é mais difícil reconhecer o sofrimento que atravessa a experiência de aprendizagem. $\mathrm{O}$ aluno, por sua vez, sem função-alfa suficiente para reconhecer e processar sua própria experiência, faz tentativas desordenadas de comunicar seu sofrimento, muitas vezes depositando-o no ambiente escolar de maneira considerada "injusta" pela instituição.

Se, nas situações descritas, o professor não tiver função-alfa suficiente à sua disposição, considerará o aluno malcomportado ou indisciplinado e tenderá a colocá-lo para fora de sala, para que medidas administrativas sejam tomadas. Em nível administrativo, o mesmo pode se repetir. Caso o diretor tenha função-alfa disponível, pode fazer uso dela para processar tanto os elementos-beta do aluno quanto do professor, produzidos nessa relação tensa com o "aluno indisciplinado". No entanto, na escola, a tendência, por parte do professor e do gestor, tem sido abordar a situação pela via do controle - de maneira prescritiva ("você deve fazer isso ou aquilo") ou corretiva -, aplicando medidas punitivas, com "o rigor da lei". Essa era normalmente a situação com a qual se deparavam os alunos indisciplinados da escola estudada.

\section{Terceiro pressuposto}

Como dito anteriormente, a ansiedade não tolerada é expelida pela mente que não dispõe de funçãoalfa suficiente em um determinado momento. Nesse sentido, basta que mudemos o vértice de observação para perceber que os elementos-beta a que se refere a indisciplina podem ser provenientes do aluno, mas não apenas dele. Podem provir do professor, do grupo-classe ou mesmo dos profissionais responsáveis pela gestão da instituição. Ou seja, ao se falar de indisciplina, não apenas o aluno está implicado, mas a totalidade da instituição. Um professor pressionado por excessivas exigências profissionais ou ainda pelo descaso institucional pode não suportar a intensidade da frustração presente nessas experiências, gerando, dessa maneira, uma tensão em sala de aula que resulte, fundamentalmente, de sua ansiedade não processada e expelida sob a forma de identificação projetiva.

Já há algum tempo tem sido grande a preocupação com a saúde dos profissionais da educação (CODO, 1999). Depoimentos de professores que se ausentam do trabalho com ou sem justificativa revelam que, muitas vezes, fazem-no por não tolerar o contato com a escola e não se sentir amparados pela instituição na tarefa que lhes cabe com os alunos todos os dias da semana. Faltam um dia, esperando recuperar forças para o dia seguinte. Ao fazerem isso, têm um alívio momentâneo. Contudo, como os elementos-beta não são processados ou pensados, produzem outro nível de desgaste: a ausência voluntária expulsa o sofrimento sob a forma de resposta hostil ou de indiferença dos professores em relação à instituição. A hostilidade e a indiferença, porém, recaem também sobre os alunos, os quais, por sua vez, veem no professor uma figura 
que os agride com sua ausência-indiferença ou uma figura frágil, incapaz de estar frente a frente com os seres (alunos) de quem deveria cuidar.

Os alunos são tomados pela violência dessa identificação projetiva vinda dos adultos, de modo difuso. Sem saber de onde vem e a que serve, reagem, num crescendo, com sarcasmo, indiferença ou outra forma de violência que o professor, mais uma vez, não suporta. Ao final, é a essa reação dos alunos que o professor e a escola dão o nome indisciplina, embora não tenha sido gerada no segmento dos alunos, apenas tenha encontrado neles um ponto de reverberação dos elementos-beta produzidos por uma instituição que não dá suficiente apoio aos professores. Essa mesma dinâmica pode ser verificada na relação entre a administração central e os gestores das unidades escolares, fazendo com que elementos não processados desencadeiem respostas igualmente não processadas entre os professores e os alunos, num efeito dominó.

\section{Quarto pressuposto}

Partindo-se da ideia de que o uso excessivo da identificação projetiva fragiliza e empobrece o sujeito, já que faz com que ele expulse de si não apenas a própria ansiedade, mas também partes de seu self, quanto menos a instituição for capaz de acolher e processar mentalmente essa ansiedade, mais frágil e vulnerável o sujeito ficará. Em outras palavras, quando os elementos-beta são nomeados como indisciplina e passam a receber um tratamento exclusivamente prescritivo ou corretivo, o aluno tende a perceber-se ainda mais desprovido de condições psíquicas para atender às exigências da escola, pois precisará arcar solitariamente não apenas com os aspectos intoleráveis de sua experiência anterior, mas também com aqueles que surgem desse enfrentamento com o professor ou com o diretor. Se ele já se encontrava em condições de maior fragilidade e esvaziamento, a pressão da escola para corrigi-lo tende a constituir nova experiência emocional intolerável - ressentimento e hostilidade inundam o psiquismo já vulnerável desse aluno, de modo que a ele só resta repetir os mecanismos de fuga (de identificação projetiva).

Não por acaso, portanto, os alunos sistematicamente "corrigidos" pelas medidas disciplinares mais extremas tendem a ter inúmeras e frequentes recidivas de indisciplina. $\mathrm{O}$ caso é ainda mais grave quando consideramos que, muitas vezes, a pressão da escola é feita mediante aliança com os pais, a qual recairá duplamente no próprio aluno.

\section{Quinto pressuposto}

Quando um sujeito vê processados por um “outro" (indivíduo, grupo, instituição) seus elementos-beta que, num dado momento, ele mesmo foi incapaz de processar, toma para si sua própria ansiedade, transformada em algo tolerável, mas não apenas isso. Recolhe também as partes perdidas de seu self e introjeta a capacidade de processamento demonstrada por esse outro, assim como o conforto de ter sido socorrido.

A título de ilustração, podemos retomar a situação descrita no primeiro pressuposto. Quando o processamento de uma experiência emocional do aluno é possível mediante a utilização da função-alfa do professor (ou de um colega, ou da direção da escola), a resposta dada ao aluno não se refere apenas a tornar tolerável ou palatável o que se passa com ele - o que já é bastante, e bem mais do que a resposta correcional e disciplinadora. Trata-se também de uma resposta que permite um espelhamento e propicia ao aluno apropriar-se dessa ferramenta de pensamento que ao outro está disponível. Além disso, trata-se de uma experiência de conforto por ter sido compreendido e atendido em sua necessidade. Oposto ao descrito no quarto pressuposto, o que ocorre aqui é o fortalecimento do sujeito. 
Tomando a situação do professor descrito no terceiro pressuposto, podemos pensar em uma classe que, em vez de reagir violentamente à identificação projetiva do professor, fique sensível ao estado dele e se comporte de maneira a oferecer maior atenção ao que ele fala. A empatia da turma para com o sofrimento do professor, muitas vezes, é suficiente para que ele recobre o entusiasmo, a esperança na educação e, por conseguinte, a capacidade de enfrentar as dificuldades inerentes ao processo; ou seja, recupere sua funçãoalfa. Esse comportamento não é incomum entre os alunos, em especial quando o estado de tensão criado pelo professor é algo esporádico. Quando, contudo, a dificuldade do professor é algo sistemático, os alunos tendem a identificar não o sofrimento pelo qual ele passa, mas apenas a agressão a que estão submetidos em virtude dele.

Às vezes, a classe percebe o estado do professor, mas não está em condições de acolher, ser continente ou ter empatia. Nesses casos, é comum que a turma se sinta responsável pelo mal-estar do professor. Em nível administrativo, o gestor também pode ser aquele que faz uso de sua função-alfa para ajudar o professor a processar alguns elementos de sua experiência, em particular aquelas relacionadas à própria profissão. Muitas das reações hostis de professores são motivadas por sofrimento intenso e não acolhido, relativo a dificuldades no cotidiano da escola e no trato tanto com alunos que não aprendem ou se mostram refratários a toda e qualquer estratégia do professor quanto com a burocracia escolar. Encontrar no gestor da escola uma figura disposta a acolher, legitimar e processar a angústia mobilizada nessas experiências pode ajudar o professor a recuperar sua própria função-alfa.

\section{Sexto pressuposto}

Como afirma Bion (2004b), nem sempre é o analista que está de posse da função-alfa, mas sim o paciente. Quando isso ocorre, o analista deve ser capaz de aceitar que a contribuição do paciente, não a sua própria, é a que permite à dupla (analista-paciente) se aproximar da verdade da experiência. O “outro", que, em tese, pode acolher e processar os elementos-beta de um sujeito, também pode ter sua funçãoalfa variando para mais ou para menos, dependendo das condições em que se encontra (p. ex., maior ou menor tensão).

Portanto, quando a função-alfa desse "outro" está disponível ao uso, pode ajudar a processar os elementos-beta que circulam na instituição. Por outro lado, quando sua função-alfa está diminuída, maior é a chance de que os elementos-beta do primeiro sujeito sejam potencializados com os desse "outro". A instituição escolar é sempre um ambiente de intensas trocas emocionais. Nem sempre o profissional de quem se espera maior lucidez está de posse de sua função-alfa. Nesses casos, o importante é avaliar de onde parte a maior capacidade de processamento das experiências emocionais ali presentes, além de confiar que as soluções para alguns problemas nem sempre partem das pessoas formalmente incumbidas dessa função. Em outras palavras, é importante que a instituição reconheça que funciona de maneira mais apropriada ou saudável se acolher o melhor uso da função-alfa, venha de onde vier - pais, secretários, vigias, merendeiras, alunos, professores ou equipe gestora.

Quando Bion (2004a) introduz o conceito de função-alfa, a ideia de compreensão - voltada para o âmbito da racionalidade -, cede lugar às ideias de continência e acolhimento que invadem o âmbito afetivo. A verdade da experiência, portanto, deixa de ser apreensível exclusivamente pela consciência e pela razão e passa a ser apreensível por uma função que exige o processamento mental das emoções contidas nessa experiência.

A capacidade de ser continente (de acolher mentalmente um conteúdo), portanto, não está mecanicamente associada a níveis de ensino, idade ou nível socioeconômico. Consequentemente, a relação entre um conteúdo e uma mente continente não é unidirecional. Embora se espere maior capacidade de 
resolver problemas e enfrentar dificuldades daqueles que possuam maior qualificação profissional, dos mais velhos e daqueles que ocupem funções de maior responsabilidade institucional, nem sempre isso ocorre. Assim se espera porque se imagina que a idade e a qualificação profissional desenvolvam a capacidade de compreensão de um maior espectro da realidade, bem como que a progressão na carreira derive dessa maior capacidade. Muitas vezes, todavia, esperamos um professor continente às necessidades da sala $\mathrm{e}$ encontramos uma sala continente para as dificuldades do professor; filhos continentes para dificuldades dos pais; merendeiras continentes para dificuldades de professores e alunos.

Ainda que a posição do profissional não implique necessariamente a disponibilidade de sua função-alfa, deve ser objetivo dele pensar-se como um agente de recuperação ou desenvolvimento da própria função-alfa e da função-alfa dos demais da instituição. Ou seja, aos gestores e aos professores caberia incansavelmente pensar em como não devolver ou potencializar os elementos-beta (não processados) que circulam na instituição e em como "conter" ou ser continente para os aspectos intoleráveis produzidos nas experiências institucionais.

\section{Para Além da Indisciplina}

Portanto, a indisciplina pode ser considerada manifestação de um ecossistema cuja capacidade de processamento dos elementos-beta ali circulantes está diminuída ou inexistente. A relação entre o conteúdo a ser processado e a mente continente, capaz de processá-lo, portanto, falha.

Daí que indisciplina não é o mesmo para pessoas e grupos diferentes (ou até para os mesmos grupos e pessoas em momentos diferentes). Ela depende da capacidade daquele ecossistema de acolher e processar o que ali circula, transformando-o em elementos disponíveis ao pensamento. Por isso, é comum vermos uma mesma instituição respondendo diferentemente (com sansões e punições distintas) a uma mesma manifestação "indisciplinada” do aluno.

Em geral, a instituição pensa a indisciplina apenas a partir da sala de aula; ou seja, o vértice de observação considera apenas a parcela do ecossistema que inclui alunos e professor. Quando os problemas começam e são manejados em sala, esse vértice é suficiente. Contudo, pode ser diferente e englobar outros profissionais e instâncias da instituição. Quando um aluno é expelido da sala e mandado para a direção, por exemplo, o vértice de observação deve considerar essas outras instâncias como parte do ecossistema, fazendo com que a relação continente-contido seja pensada também em função desses outros segmentos (quem contém, o que é o conteúdo a ser contido, de quem parte o conteúdo), pois haverá um emaranhado entre sala, aluno expelido, direção e professor. A demanda por continência virá de várias partes. O professor que não conseguiu ser continente para a manifestação do aluno e que está dominado por seus próprios elementos-beta exigirá uma resposta, por vezes impossível, da direção. Nesses casos, e se os elementos-beta do professor não excederem demasiadamente sua função-alfa, ele poderá demandar continência tanto para ele mesmo quanto para o aluno. Se a situação for mais grave, o professor poderá exigir que a direção ofereça continência para ele, mas que promova a retaliação do aluno. Pode, por exemplo, reivindicar que o gestor use sua autoridade e sua posição para forçar para dentro do aluno (identificação projetiva) os aspectos mais destrutivos da instituição, fazendo-o sentir-se a escória não pertencente e não desejada pela instituição. Em outras palavras, nesses casos, o professor acaba por exigir, sem perceber, que o diretor sirva de veículo para a projeção de seus elementos-beta sobre o aluno.

Para que possa refletir e agir sobre a indisciplina, a escola precisa considerar que a manifestação da indisciplina é problema institucional, em termos de um ecossistema que falhou no processamento dos elementos-beta - não de um sujeito sem lugar e sem história. 
É possível antecipar-se a alguns problemas relacionados à indisciplina, identificando situaçõeslimite, em que há maior probabilidade de os elementos-beta não encontrarem função-alfa disponível para processá-los. Contudo, nas situações já instaladas, é preciso identificar quais desses elementos estão envolvidos no processo (culpa, desamparo e hostilidade são alguns deles). Levantar hipóteses sobre eles permite que a intervenção seja mais efetiva.

É também necessário indagar se a escola desencadeou as experiências às quais os elementos-beta se referem. É fundamental diferenciar as experiências de sofrimento que têm origem na própria instituição daquelas que são extraescolares. A escola tem responsabilidade de intervir em ambas, já que se manifestam em seu interior, mas as intervenções podem ter características diferentes. Mesmo nos casos em que os elementosbeta ali presentes sejam predominantemente comunicações de experiências extraescolares, feitas mediante o uso da identificação projetiva, cabe à escola acolher tal comunicação. Ao fazê-lo, a instituição reconhece e legitima o sofrimento do sujeito e, ao fazê-lo, oferece oportunidade para que ele desenvolva recursos psíquicos de enfrentamento e superação.

Caso os elementos-beta se originem nas experiências intramuros - e, muitas vezes, isso ocorre -, além de acolher a experiência de sofrimento, cabe à escola, sobretudo, revisar as práticas educacionais que o impõem aos sujeitos. Tais práticas podem ser racistas; homofóbicas; meritocráticas; de indiferença em relação a injustiças; de cobranças excessivas; de desvalorização da capacidade do aluno ou dos demais membros da instituição; de subtração de espaços de socialização; de ensino pouco ou nada significativo; de pressões profissionais descabidas; de excessiva hierarquização interna; de submissão excessiva e acrítica às políticas educacionais; e de aniquilamento do potencial criativo das pessoas - para lembrar apenas alguns nossos conhecidos.

Assim, não se trata de identificar culpados. Trata-se de se pensar que cabe ao adulto responsável pelo encaminhamento das medidas disciplinadoras não a função de correção, mas de processamento das ansiedades presentes nos episódios relacionados à indisciplina. Em outros termos, trata-se, de um lado, de ser capaz de oferecer espaço mental e continência para aqueles que, em dado momento, são os depositários dos elementos-beta não transformados em elementos-alfa na instituição. De outro, trata-se de reconstruir a instituição, para que ela seja capaz de oferecer uma rede de proteção e cuidado aos seus membros, ao mesmo tempo que os desafia e encoraja a dar o melhor de si, tanto ensinando quanto aprendendo. É disso que é feita uma escola significativa (VILLELA; ARCHANGELO, 2013). É assim que a indisciplina deixa de ocupar o centro das preocupações da instituição.

\section{Notas}

1. "Pensar os pensamentos", em termos bionianos, difere de "pensar sobre eles", pois exige deixar-se atravessar por aquilo que deriva da experiência, e não apenas uma tarefa sobre a qual podemos nos debruçar intelectualmente.

\section{Referências}

ARCHANGELO, A. (org.). Professores que não jogaram a toalha. São Paulo: Loyola, 2014.

BION, W. R. Estudos psicanalíticos revisados (Second Thoughts). Rio de Janeiro: Imago, 1994.

BION, W. R. Learning from experience. Maryland: Jason Aronson, 2004a. 
BION, W. R. Transformações: Do aprendizado ao crescimento. 2. ed. Trad. Paulo Cesar Sandler. Rio de Janeiro: Imago, 2004b.

CODO, W. Educação: Carinho e trabalho. Petrópolis: Vozes, 1999.

KLEIN, M. Inveja e gratidão e outros trabalhos. 4. ed. Trad. Elias Mallet da Rocha. Rio de Janeiro: Imago, 1991.

VILLELA, F. C. B.; ARCHANGELO, A. Fundamentos da escola significativa. São Paulo: Loyola, 2013.

\section{Sobre a Autora}

Ana Archangelo é Graduada em Psicologia pela Pontifícia Universidade Católica de São Paulo em 1988. Mestre (1995) e Doutora (1999) em Educação pela Universidade Estadual de Campinas. Realizou estudos pósdoutorais na Univesity of the West of England; na University of Colchester; e no Dipartimento di Psicologia, da Università degli Studi di Torino (2011). Livre-docente (2019) pela Unicamp. Líder do grupo de pesquisa DiS (Diferenças e Subjetividades em Educação), junto ao CNPq.

Recebido: 29 mar. 2020

Aceito: 18 jun. 2020 